\title{
The Effect of Grinding on Strength of Hot-pressed Silicon Nitride
}

\author{
Hisao MIYASATO, Hiromi OKAMOTO, Shun-ichi USUI, Akira MIYAMOTO and Yasushi UENO
}

Advanced Technology Research Center, NKK Corporation, Minamiwatarida-cho, Kawasaki-ku, Kawasaki, Kanagawa-ken, 210 Japan.

(Received on December 9, 1988; accepted in the final form on March 10, 1989)

\begin{abstract}
Though the high efficient grinding technique for ceramics using a high rigid machining center with a durable diamond wheel has recently been developed, the effect of grinding flaws on material strength has not yet been clarified. So experimental investigation was conducted for evaluating the effect of machining on strength of silicon nitride, and the effects of grinding wheel, grit size and depth of cut were investigated. The strength data were analyzed by Weibull statistics. The depth of flaw in the surface, induced by high efficient grinding perpendicular to tensile stress, was about $40 \mu \mathrm{m}$. The strength of samples ground parallel to tensile stress was not decreased compared with the strength of lapped samples. The high efficient grinding generated compressive residual stress of $590 \mathrm{MPa}$ in the surface.
\end{abstract}

KEY WORDS: silicon nitride; grinding; surface flaw; bending strength; machining center; residual stress.

\section{Introduction}

Since engineering ceramic materials have many excellent properties concerned with wear, corrosion and high temperature strength, there has been considerable interest in the use of ceramic components to achieve high efficiency in automobile engines and gasturbines. While advanced forming and firing techniques make it possible to fabricate near net shaped complex ceramic components, machining is still required to produce close dimensional tolerances. But excellent properties of ceramics make it difficult to machine ceramic components and increase the machining cost over to $60 \%$ of the total fabricating cost. Moreover, though many machining techniques have been developed to fabricate steel components, only a few methods, e.g., grinding, can be applied to machine ceramic components. It prevents ceramic parts to be widely used as machine components.

Recently a durable diamond wheel has been developed, and a high efficient machining technique of ceramic materials using machining center with high rigid spindle has also been presented.1) This technique is expected to reduce the time and cost of machining. But it is generaly considered that machining flaws are induced in the high efliciently machined surface and reduce the inherent material strength, and it is also well-known that grinding directions and machining parameters affect on material strength. ${ }^{2-5}$ ) So the effect of high efficient grinding on strength of silicon nitride using machining center and diamond wheels is investigated in this study.

\section{Experimental Procedures}

\subsection{Measurement of Grinding Forces}

In this study, hot pressed silicon nitride was selected for the investigation. Some of its mechanical properties are given in Table 1. A horizontal ma- chining center with $11 \mathrm{~kW}$ continuous spindle power was used for grinding in the present work. The main specifications of the machine are given in Table 2. In order to select the optimum grinding wheel and parameters for stable and high efficient machining operation, tangential and normal grinding forces were measured with a work piece dynamometer which can measure three orthogonal components of force. Cast iron bonded, resin bonded and metal bonded diamond wheels, listed in Table 3, wcre used. The method of grinding force measurement is illustrated in Fig. 1.

Table 1. Properties of ceramics used for machining.

\begin{tabular}{lc}
\hline Material & $\mathrm{Si}_{3} \mathrm{~N}_{4}$ \\
Density $\left(\mathrm{g} / \mathrm{cm}^{3}\right)$ & 3.26 \\
Modulus of elasticity $(\mathrm{GPa})$ & 310 \\
Fracture toughness $\left(\mathrm{MPam}{ }^{1 / 2}\right)$ & 5 \\
Vickers hardness $(\mathrm{GPa})$ & 16 \\
Thermal conductivity $(\mathrm{W} / \mathrm{mK})$ & 29 \\
Coefficient of thermal expansion $(\mathrm{l} / \mathrm{K})$ & $3.2 \times 10^{-6}$ \\
\hline
\end{tabular}

Table 2. Specifications of machining center.

$\begin{array}{ll}\text { Type } & \text { MAKINO MC86 } \\ \text { Spindle motor }(\mathrm{kW} \text { conti./kW 30 min) } & 11 / 15 \\ \text { Spindle speed }(\mathrm{rpm}) & 10-5000 \\ \text { Range of movement }(\mathrm{mm}) & 810 \times 635 \times 635 \\ \text { Tool shank } & \text { MAS } 403-\mathrm{BT} 50\end{array}$

Table 3. Wheel specifications.

\begin{tabular}{lcccc}
\hline & $\begin{array}{c}\text { Grit } \\
\text { size }\end{array}$ & $\begin{array}{c}\text { Bond } \\
\text { type }\end{array}$ & $\begin{array}{c}\text { Diameter } \\
(\mathrm{mm})\end{array}$ & $\begin{array}{c}\text { Width } \\
(\mathrm{mm})\end{array}$ \\
\hline $\begin{array}{c}\text { SD200N100FA } \\
\text { 1A1 }\end{array}$ & 200 & Cast iron & 150 & 10 \\
$\begin{array}{c}\text { SDC140T100B } \\
\text { 1A1 }\end{array}$ & 140 & Resin & 150 & 10 \\
$\begin{array}{c}\text { SI140Q100M } \\
\text { IA1 }\end{array}$ & 140 & Metal & 150 & 10 \\
$\begin{array}{c}\text { SD800N75B } \\
\text { IA1 }\end{array}$ & 800 & Resin & 150 & 10 \\
\hline
\end{tabular}




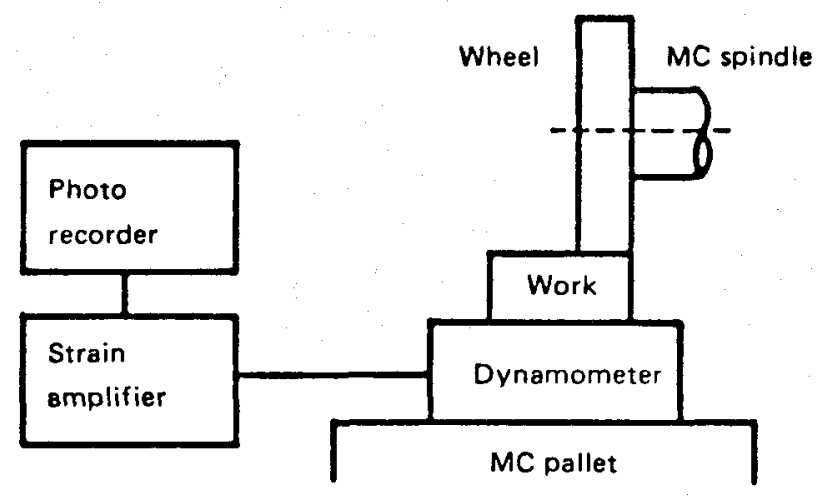

Fig. 1. Measuring instruments of grinding force.

Truing of the wheel was accomplished by a rotary truing device before each grinding experiment. Dressing was also done by a stick dressor.

\section{2. $\quad$ Strength Testing}

First, a $4 \times 4 \times 36 \mathrm{~mm}$ test piece was sliced and ground (the surface roughness value $R_{\text {tax }}$ is about 0.8 $\mu \mathrm{m}$ ) from a silicon nitride billet. The all edges of the test pieces were chamfered by lapping with Carborundum paper. The primary ground samples were bonded on a flat steel fixture, and one $4 \times 36 \mathrm{~mm}$ surface was ground or lapped to about $4 \times 3 \mathrm{~mm}$ sectional dimensions according to constant machining condition. In order to investigate the depth of machining damage layer in the high efficiently ground surface, lapping or finish grinding was gradually done in the high efficiently ground surface. After chamfering of edges in the same way described previously, the strength of machined samples was measured by bending test. Fig. 2 shows the machining procedure of the test pieces. In this study, grinding directions were parallel to the length of the specimen or perpendicular as shown in Fig. 3. Finish grinding was always done in the same direction of high efficient grinding. Every test piece was ground only by down grinding.

Removed thickness of finish grinding and lapping was measured with micrometer which can detect a minimum of $1 \mu \mathrm{m}$ length. Thickness was always measured at the center of the test piece where maximum tensile stress is applied in bending test. Strength measurement of machined materials was conducted with the three point bending test at room temperature in conformity to Japanese Industrial Standard (JIS R 1601). All specimens were loaded to apply tensile stress in the machined surface noted in this study.

\subsection{Examination of Machined Surfaces and Surface Rough- ness}

The ground and lapped surfaces of the specimens were visually examined using scanning clectron microscopy (SEM). The surface roughness of each sample machined at different conditions was measured with a surface roughness measuring instrument which has a diamond stylus. The data were obtained as chart traces.

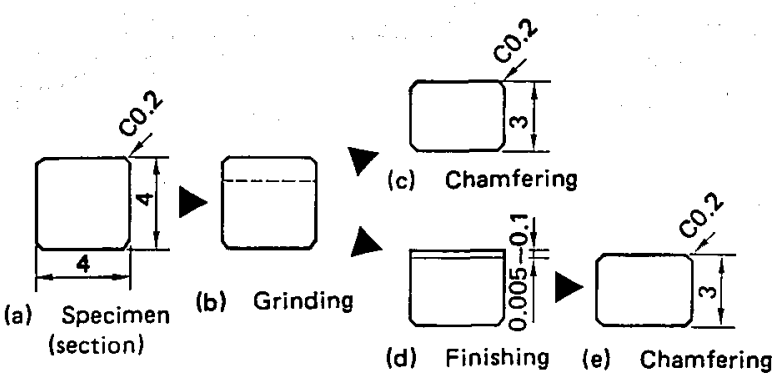

Fig. 2. Machining sequence of specimen for bending test.

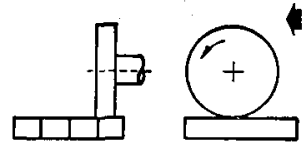

(a) Paralle!

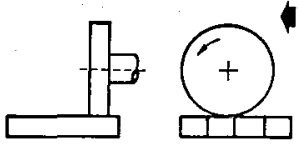

(b) Perpendicular
Fig. 3. Grinding direction.

\subsection{Measurement of Residual Stress}

The residual stresses in the machined surfaces were measured using an X-ray diffraction technique. The measurement was done for the (411) diffraction plane using Cr-radiation, with penetration depth of $10 \mu \mathrm{m}$ or less. The X-ray elastic constant $(E /(1+\nu)=246$ $\mathrm{GPa}$, where $E$ is Young's modulus and $\nu$ is Poisson's ratio) was obtained from the calibration measurements. ${ }^{6}$

\section{Results and Discussion}

\subsection{Durability of Grinding}

The variations of the tangential force $\left(F_{t}\right)$ and the normal force $\left(F_{n}\right)$ during grinding samples with each grinding wheel were shown in Fig. 4. The samples were ground with the peripheral wheel speed $(V)$ of $2000 \mathrm{~m} / \mathrm{min}$, the feed spced $(f)$ of $15 \mathrm{~m} / \mathrm{min}$, the grinding width of $2 \mathrm{~mm}$ and the depth of cut $(d)$ of 0.1 and $0.2 \mathrm{~mm}$. As reported in Ref. 7), no significant increase in the grinding force could be observed with a cast iron bonded wheel. Fig. 4(a) shows that metal bonded and resin bonded wheels also could grind silicon nitride at such a high efficient removal rate of $1500 \mathrm{~mm}^{3} / \mathrm{mm} \cdot \mathrm{min}$. Moreover, when resin bonded wheel was used, the grinding forces were the lowest among three wheels.

In order to investigate the effect of depth of cut, the samples were ground with $0.2 \mathrm{~mm}$ depth of cut. In this grinding condition, the average grinding force values were about twice as large as the values with $0.1 \mathrm{~mm}$ depth of cut as shown in Fig. 4(b). In the case of the grinding using resin bonded wheel with $0.2 \mathrm{~mm}$ depth of cut, the normal forces were significantly increased and grinding of more than 1000 $\mathrm{mm}^{3} / \mathrm{mm}$ stock removal could not be conducted. Metal bonded and cast iron bonded wheels indicate almost the same grinding characteristic, though coarser grit of metal bonded wheel generated larger grinding forces.

The difference between the intended total depth of cut and the actually machined depth of cut using 


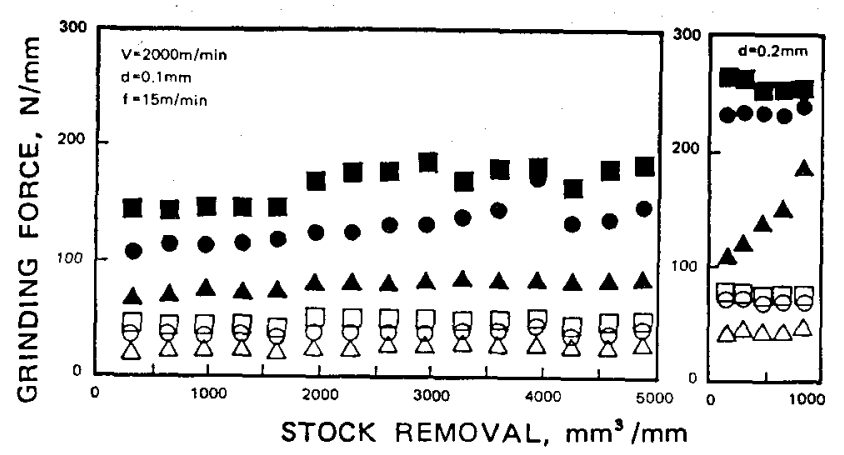

$\begin{array}{ll}\text { (a) } d=0.1 \mathrm{~mm} & \text { (b) } d=0.2 \mathrm{~mm}\end{array}$

\begin{tabular}{ccc}
\hline$F_{t}$ & $F_{n}$ & Wheel \\
\hline$\bigcirc$ & $\bullet$ & SD200N100FA \\
$\square$ & $\square$ & SD140Q100M \\
$\Delta$ & $\Delta$ & SDC140T100B
\end{tabular}

Fig. 4. Variation of grinding force with stock removal.

each wheel was less than $0.05 \mathrm{~mm}$, hence no significant problem was produced in regard of the unground remains.

\subsection{Bending Strength Testing}

3.2.1. Effect of Grinding Direction

In order to investigate the effect of grinding direction on strength, sets of 20 test pieces machined with the stable grinding condition were used. The grinding condition is given in Table 4 [1]. The sets of test pieces were ground parallel to the length of the specimen or perpendicular to it, and the other set of test pieces was lapped with $1 \mu \mathrm{m}$ diamond grit as given in Table 5, in order to compare with the ground samples. The Weibull plots of bending strength of samples machined with these conditions are shown in Fig. 5.

The average strengths $\left(\sigma_{\mathrm{mb}}\right)$ of samples ground parallel to the length of the specimen and lapped as mirror were 850 and $810 \mathrm{MPa}$, and the Weibull modulus (w.m.) were 20 and 12 , respectively. No significant difference in the average strength can be observed. In the grinding perpendicular to the length of the specimen, tensile stress is generated perpendicularly to the grinding direction. In this case, the average strength and the Weibull modulus were $470 \mathrm{MPa}$ and 12 , respectively. The strength was $40 \%$ lower than the case of grinding parallel to the length of the specimen. Hence it was considered that the surface flaws were generated along the grinding direction.

\subsubsection{Finish Grinding}

In order to investigate the surface damage induced by the high efficient grinding, several finish grinding conditions of removing the damaged layer were tested and the optimum condition was determined. It can recover the strength of material and provides a method of machining ceramics at high speed without sacrificing the quality of the ground components. The test pieces ground using an 800 grit resin bonded wheel with the condition as given in Table 4 [2], were lapped with $1 \mu \mathrm{m}$ diamond grit gradually. The bending test results in cases of the parallel grinding
Table 4. Grinding conditions.

\begin{tabular}{llllc}
\hline No. & Wheel & $\begin{array}{c}\text { Wheel } \\
\text { speed } \\
(\mathrm{m} / \mathrm{min})\end{array}$ & $\begin{array}{c}\text { Depth of } \\
\text { cut } \\
(\mathrm{mm})\end{array}$ & $\begin{array}{c}\text { Feed } \\
\text { speed } \\
(\mathrm{m} / \mathrm{min})\end{array}$ \\
\hline$[1]$ & SD200N100FA & 2000 & 0.1 & 15 \\
{$[2]$} & SD800N75B & 2000 & 0.002 & 0.6 \\
{$[3]$} & SD200N100FA & 2000 & 0.02 & 15 \\
{$[4]$} & SDC140T100B & 2000 & 0.02 & 15 \\
\hline
\end{tabular}

Table 5. Lapping conditions.

\begin{tabular}{ll}
\hline Lap & Steel, Silk \\
Abrasive & Synthetic diamond \\
Grit size $(\mu \mathrm{m})$ & 3,1 \\
Table speed $(\mathrm{m} / \mathrm{min})$ & 140 \\
Pressure $(\mathrm{MPa})$ & 0.1 \\
Fluid & Ethanol \\
\hline
\end{tabular}

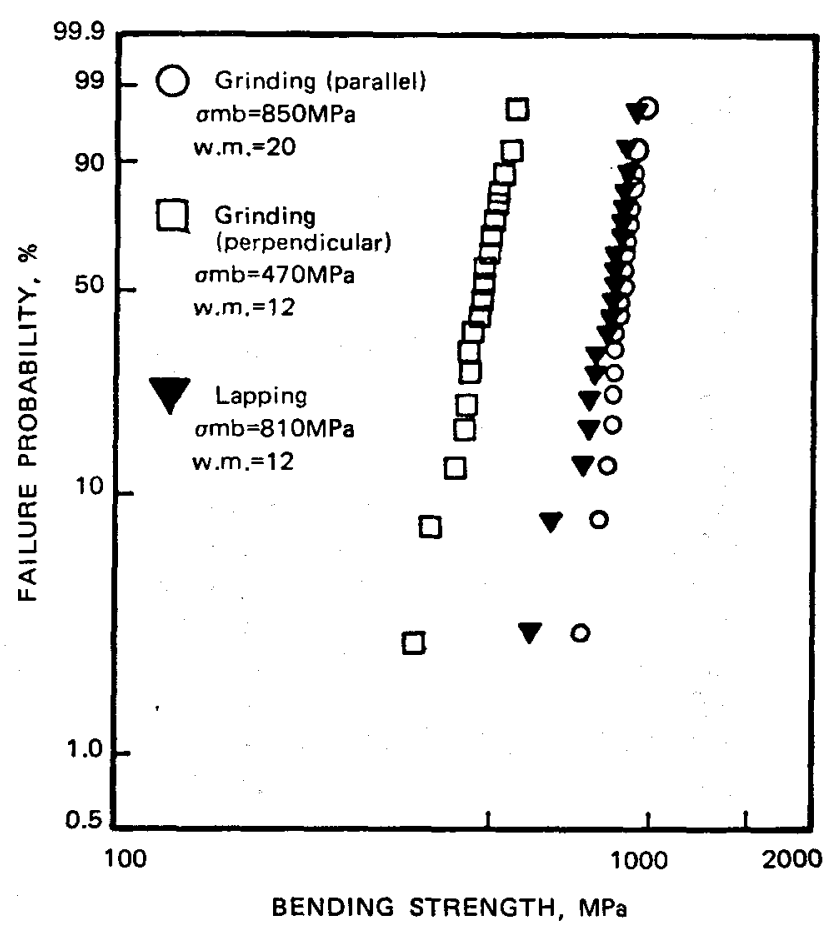

Fig. 5. Weibull distribution of bending strength of machined $\mathrm{Si}_{3} \mathrm{~N}_{4}$.

and the perpendicular grinding are shown in Figs. 6 and 7, respectively. From these figures, it is found that the strengths of samples which were gradually lapped are not higher than that of ground samples in each case, though the scatter in the strength data is considerably large. Hence it could be regarded that the primary grinding with 800 grit resin bonded wheel was appropriate to finishing of the high efficiently ground surface.

\subsubsection{Strength Recovery by Finish Grinding}

The relation between depth removed by finish grinding with 800 grit resin bonded wheel and bending strength is shown in Fig. 8. Prior to finish grinding, the surfaces of the bending test pieces were high efficiently ground perpendicular to the length of the specimen with 200 grit cast iron bonded wheel with the condition which was given in Table 4 [1]. The 
purpose of the finish grinding was to investigate whether the surface damage introduced by the high efficient grinding could be removed entirely.

As shown in Fig. 8, the strengths of finish ground samples about $40 \mu \mathrm{m}$ depth from the high efficiently ground surface were recovered to the strength of samples ground parallel to the length of the specimen. Hence, it was considered that there was a $40 \mu \mathrm{m}$ depth of the surface flaw in the high efficiently ground surface, assuming that the finish grinding with 800 grit resin bonded wheel did not extend the surface

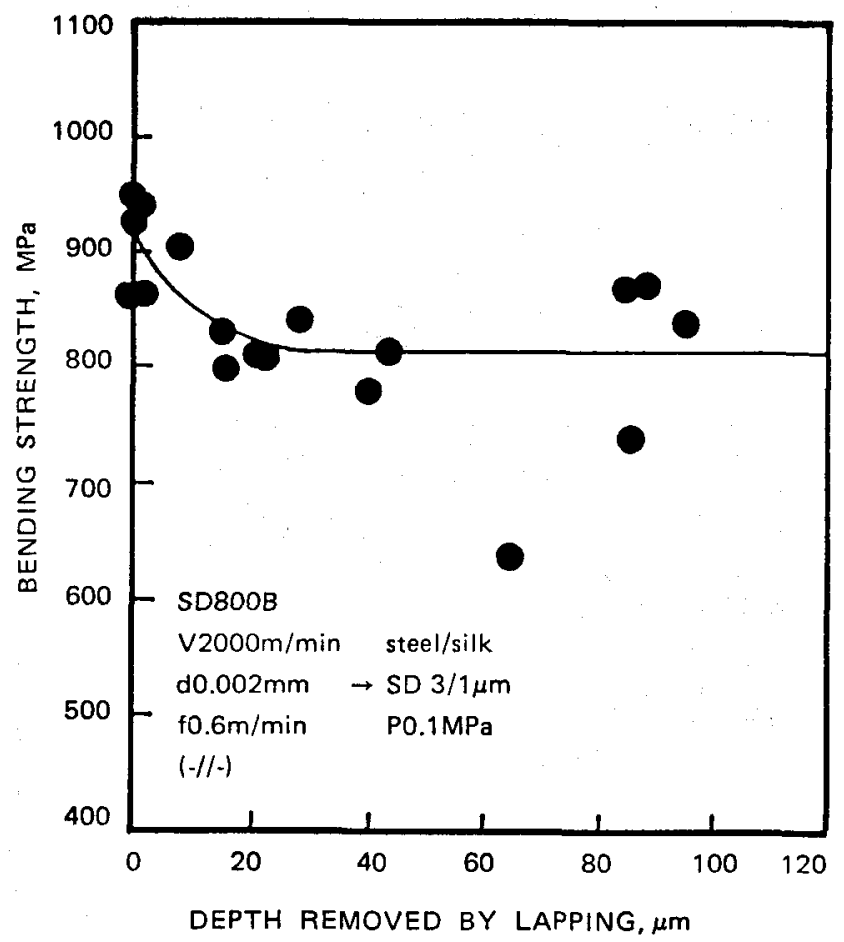

Fig. 6. Variation of bending strength with depth removed by lapping. flaws. Meanwhile no increase has been recognized in strength after the finish grinding in the case of the parallel grinding as shown in Fig. 9, so the flaws which decrease the strength have not been generated in the surface high efficiently ground parallel to the length of the specimen.

In order to investigate relation between the depth of cut and the strength of samples ground perpendicular to the length of the specimen, the test pieces were ground with $0.02 \mathrm{~mm}$ depth of cut with a 200 grit cast iron bonded wheel or with a 140 grit resin bonded

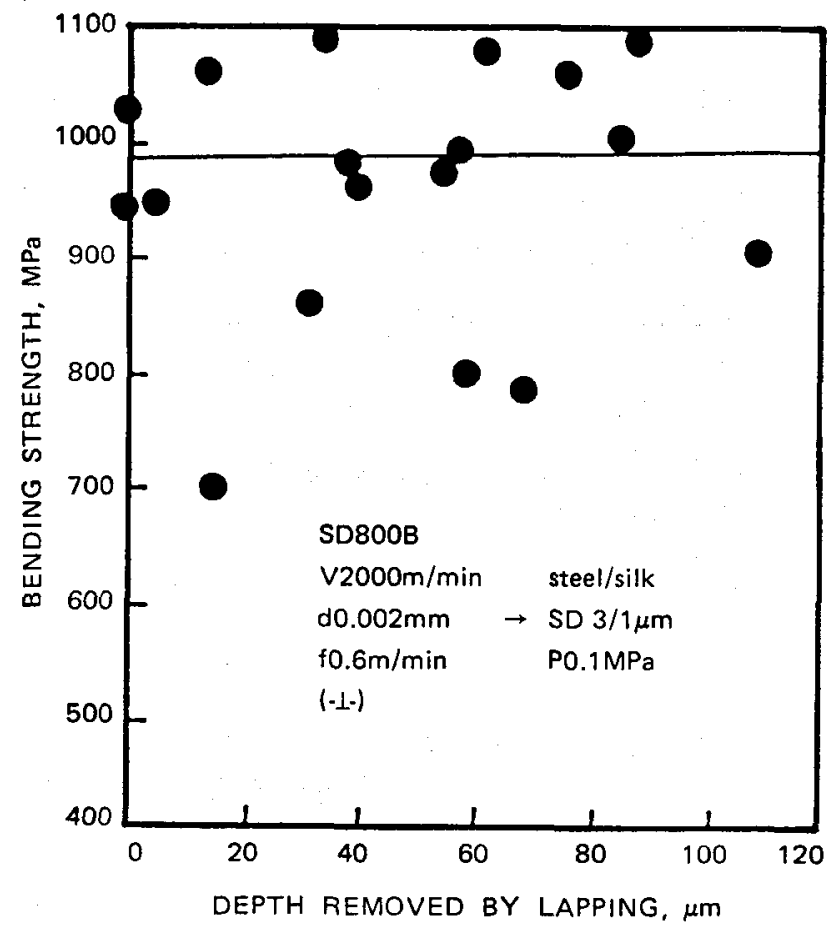

Fig. 7. Variation of bending strength with depth removed by lapping.
Fig. 8.

Variation of bending strength with depth removed by grinding perpendicular to bending direction.

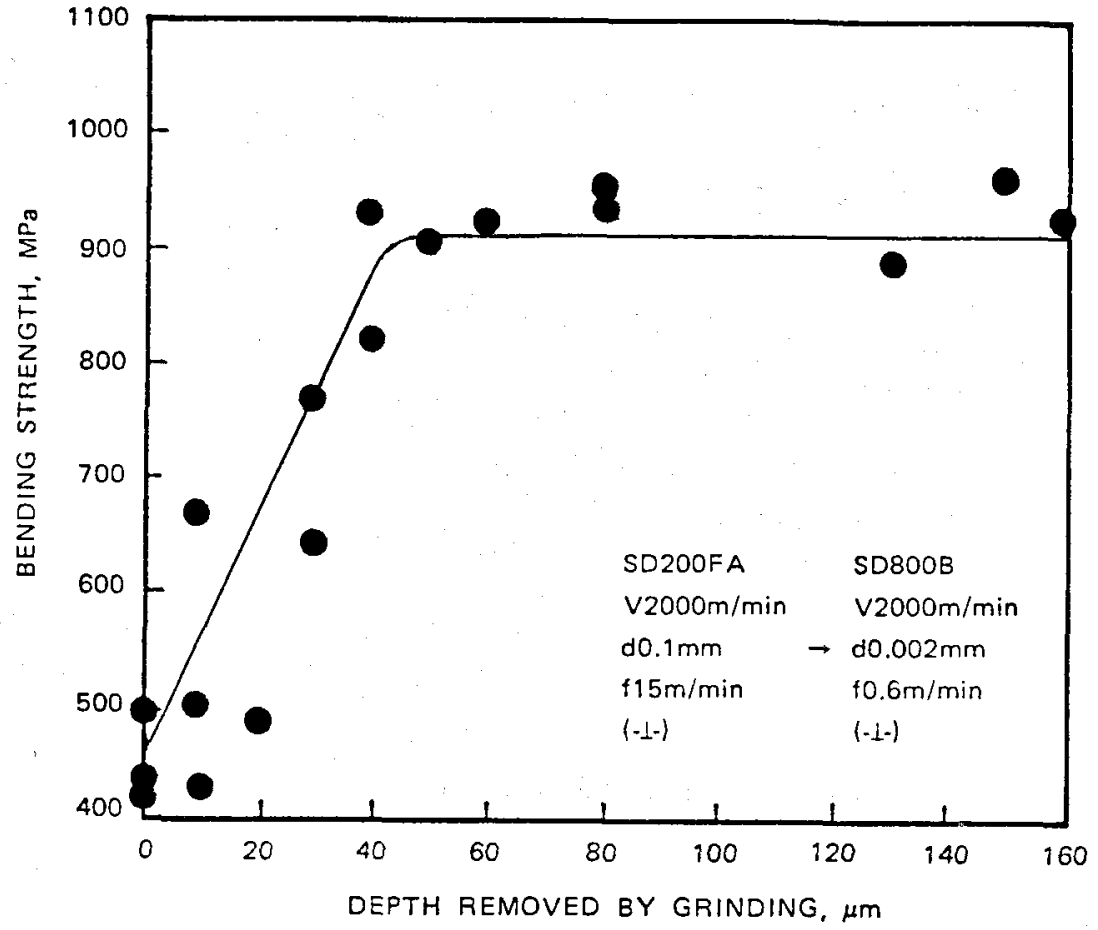




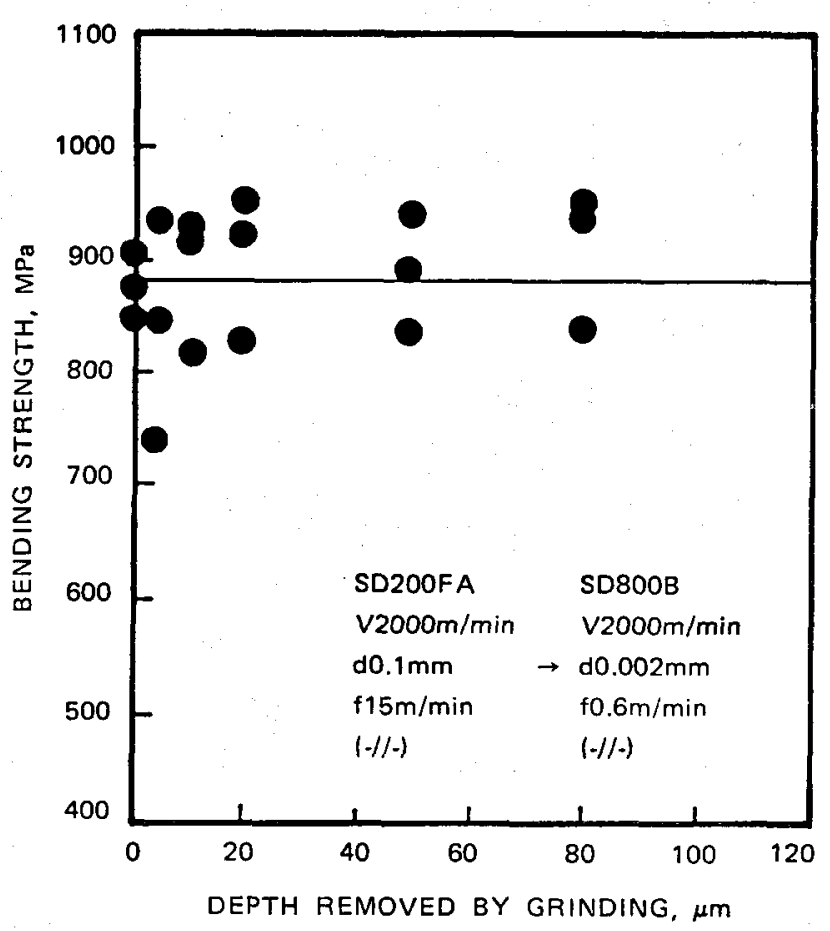

Fig. 9. Variation of bending strength with depth removed by grinding parallel to bending direction.

wheel. The machining conditions in these experiments are given in Table 4 [3], [4], and the relations between the depth removed by finish grinding and the strength ground with cast iron bonded whecl or resin bonded wheel were shown in Figs. 10 and 11, respectively.

The machining efficiency in these grinding conditions is $20 \%$ of the efficiency which is indicated in the grinding with $0.1 \mathrm{~mm}$ depth of cut, and it is regarded that the grinding with $0.02 \mathrm{~mm}$ depth of cut can be done with a surface grinding machine which has ordinary rigidity of wheel spindle. As it was seen in the figures, the bending strength of samples ground with $0.02 \mathrm{~mm}$ depth of cut was about $550 \mathrm{MPa}$, and about $30 \mu \mathrm{m}$ depth removal was needed to recover its original strength. Hence, the finish allowance which is needed to recover the original strength of the sample is about $10 \mu \mathrm{m}$ smaller than the case of the grinding with the condition given in Table 4 [1]. It was considered that the surface flaws were smaller than that induced by the grinding with $0.1 \mathrm{~mm}$ depth of cut, owing to the smaller grinding force.

\subsection{Machined Surface Observation and Surface Roughness}

The SEM photographs and roughness charts of surfaces machined with different machining conditions are shown in Fig. 12. No significant difference could be observed in the photograph (a), ground with 0.1 $\mathrm{mm}$ depth of cut, compared with the photograph (d), ground with $0.02 \mathrm{~mm}$ depth of cut. And there was not a significant difference in these surface roughness either. The grinding grooves could not be observed in the finish grinding photograph (b), hence it was considered that the subsurface flaws induced to the direction of grooves were so small that the strength

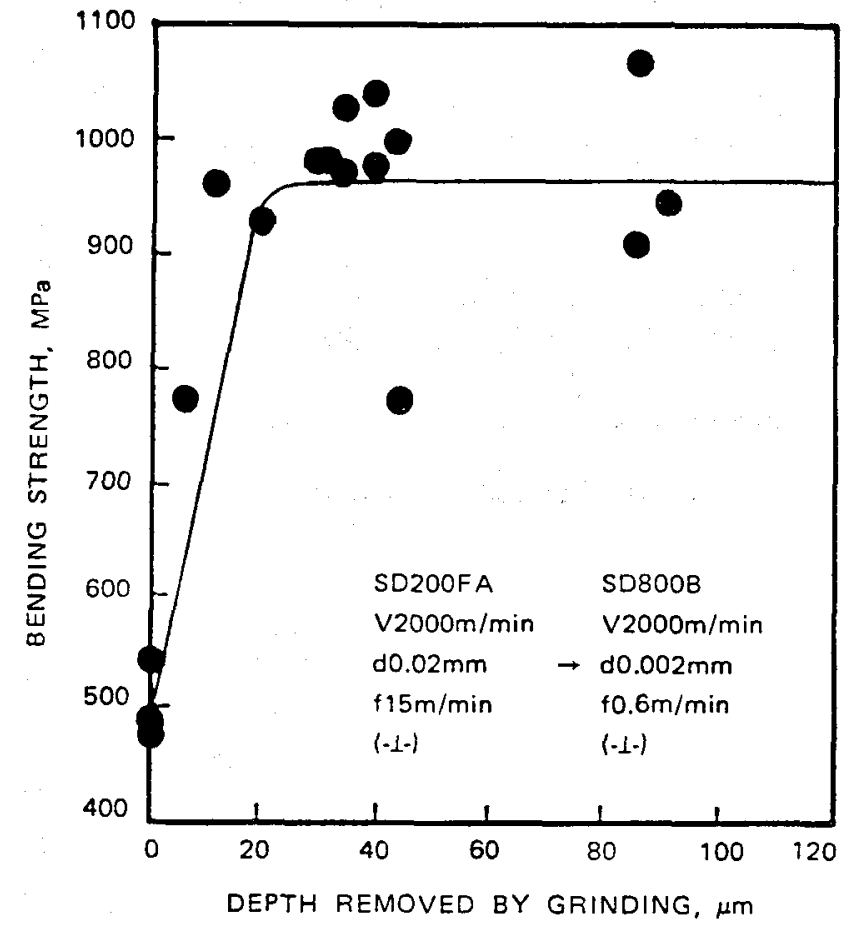

Fig. 10. Variation of bending strength with depth removed by grinding perpendicular to bending direction.

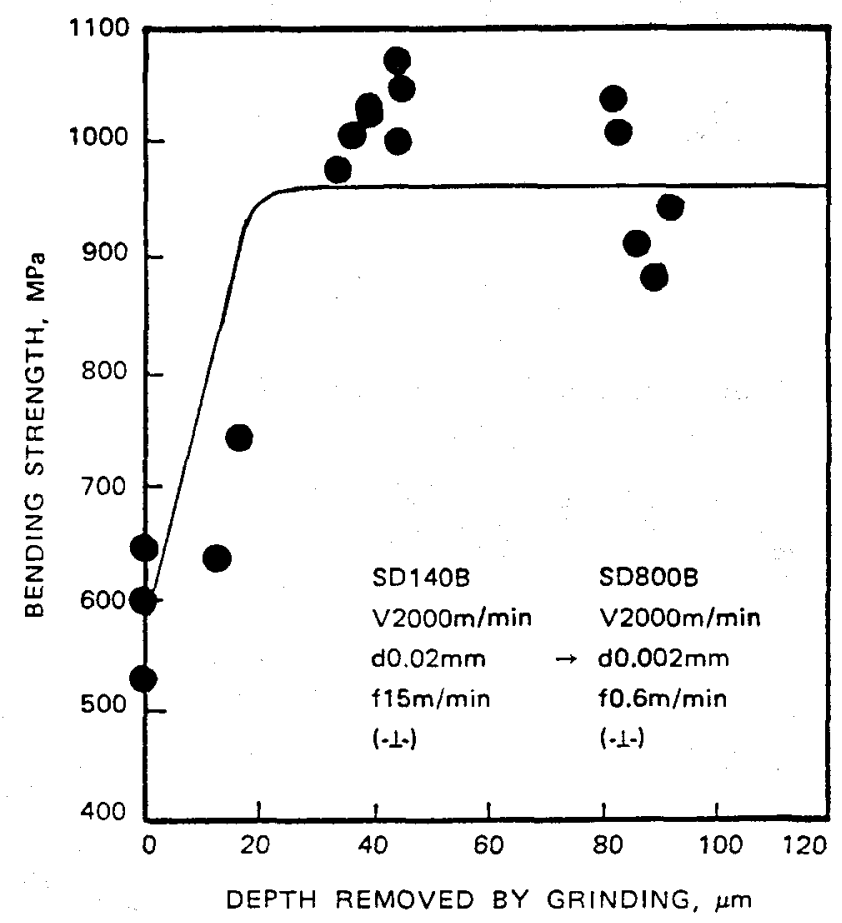

Fig. 11. Variation of bending strength with depth removed by grinding perpendicular to bending direction.

did not decrease. The photograph (e) and its surface profile, ground with coarser grit diamond wheel, showed more rough surface in comparison with the photograph (d), though the other grinding conditions were the same. And a typical lapped surface which is regarded as flawless surface is shown in the photograph (c). The roughness of the lapped surface was too small to decrease the original strength of the material. 

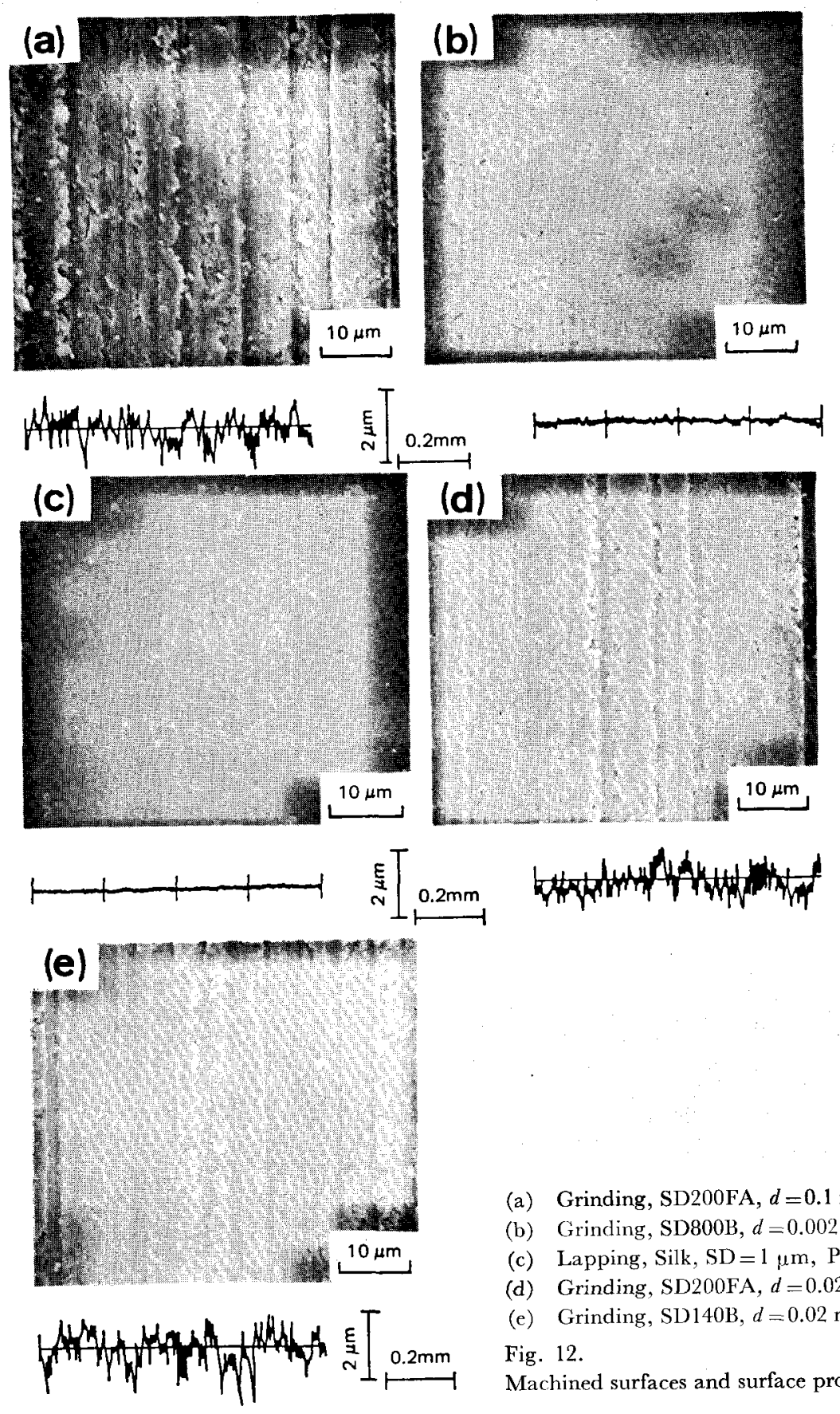

(a) Grinding, SD200FA, $d=0.1 \mathrm{~mm}, f=15 \mathrm{~m} / \mathrm{min}$

(b) Grinding, SD800B, $d=0.002 \mathrm{~mm}, f=0.6 \mathrm{~m} / \mathrm{min}$

(c) Lapping, Silk, $\mathrm{SD}=1 \mu \mathrm{m}, \mathrm{P}=0.1 \mathrm{MPa}$

(d) Grinding, SD200FA, $d=0.02 \mathrm{~mm}, f=15 \mathrm{~m} / \mathrm{min}$

(e) Grinding, SD140B, $d=0.02 \mathrm{~mm}, f=15 \mathrm{~m} / \mathrm{min}$

Fig. 12.

Machined surfaces and surface profiles of $\mathrm{Si}_{3} \mathrm{~N}_{4}$.

Next, the SEM photographs of the surfaces which were lapped with $1 \mu \mathrm{m}$ diamond grit in the surfaces ground with the condition as given in Table 4 [1], are shown in Fig. 13. The lapped surfaces which were removed of 4,12 , and $34 \mu \mathrm{m}$ depth from the ground surface (a) are shown in the photographs (b) to (d), respectively. As the pore was observed along the groove in the photograph (c), it was found that the subsurface flaws were generated parallel to the grinding direction. And in the photograph (d), neither flaw nor pore was seen. Hence it was considered that the depth of the flaws generated along the groove was about $40 \mu \mathrm{m}$ from the surface and it was consistent with the bending test results.

Assuming that there is an edge-notched flaw which is elongated to the depth, $C$, at the center of the bending test piece, the relation between the three point bending strength, $\sigma_{b}$, and the flaw size, $C$, is given by the expression

$$
\kappa_{\mathrm{IC}}=Y_{\sigma_{b}}(\pi C)^{1 / 2}
$$

where, $K_{\mathrm{IC}}$ : the critical stress intensity factor

$Y$ : a constant which accounts for the flaw shape and the type of loading.

In this study, as $K_{\mathrm{IC}}$ is $5 \mathrm{MPam}^{1 / 2}$ and $Y$ is 1 on the assumption that the machining flaw is edge-notched through the width of the specimen, the bending strength $\left(\sigma_{b}\right)$ is $500 \mathrm{MPa}$ when the flaw size $(C)$ is 30 $\mu \mathrm{m}$, and $\sigma_{b}$ is $400 \mathrm{MPa}$ when $C$ is $40 \mu \mathrm{m}$. Hence the bending test results in Figs. 8, 10, and 11 were almost compatible with these calculated values. However it is necessary to investigate the effect of residual stress and the complicated existence of surface flaws on strength exactly. 

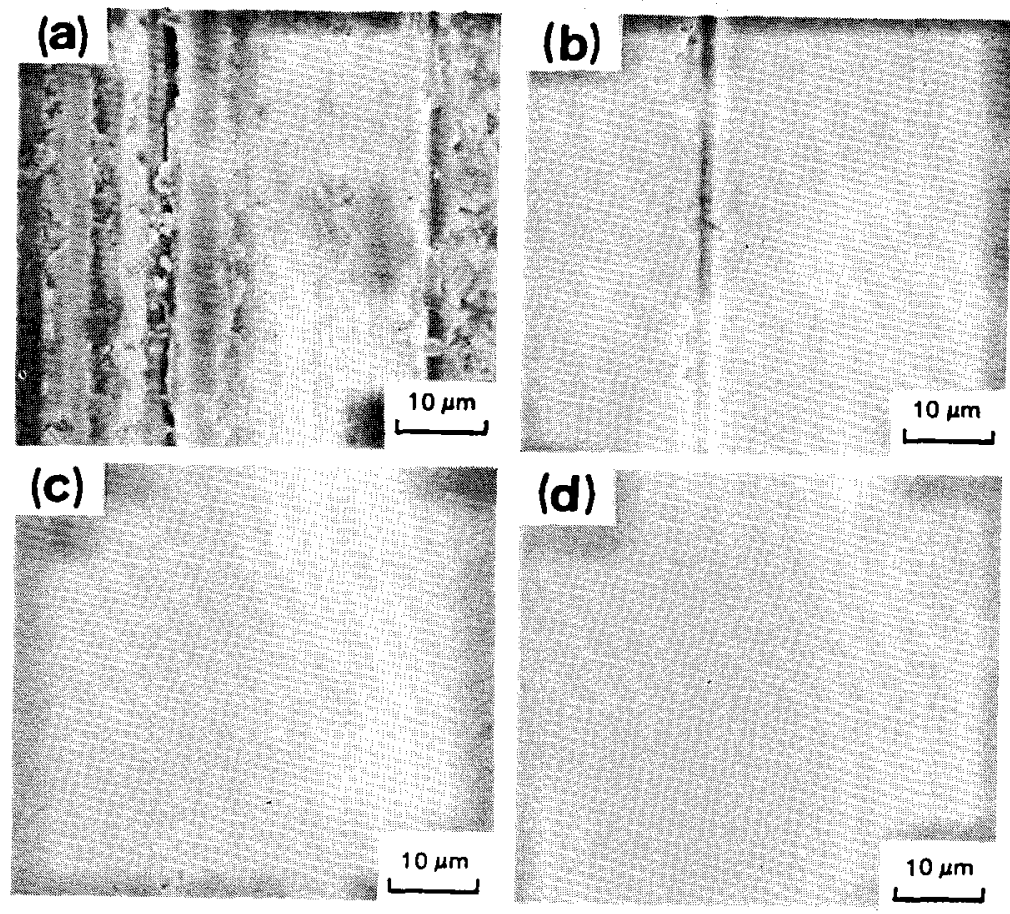

(a) Ground surface before lapping, SD200FA, $d=0.1 \mathrm{~mm}, f=15 \mathrm{~m} / \mathrm{min}$

(b) $4 \mu \mathrm{m}$ depth removed from the surface (a)

(c) $12 \mu \mathrm{m}$ depth removed from the surface (a)

(d) $34 \mu \mathrm{m}$ depth removed from the surface (a)

Fig. 13.

Lapped surfaces of $\mathrm{Si}_{3} \mathrm{~N}_{4}$.

Fig. 14.

Relation between $2 \theta$ and $\operatorname{SIN}^{2} \Psi$, X-ray residual stress measurements in $\mathrm{Si}_{3} \mathrm{~N}_{4}$.

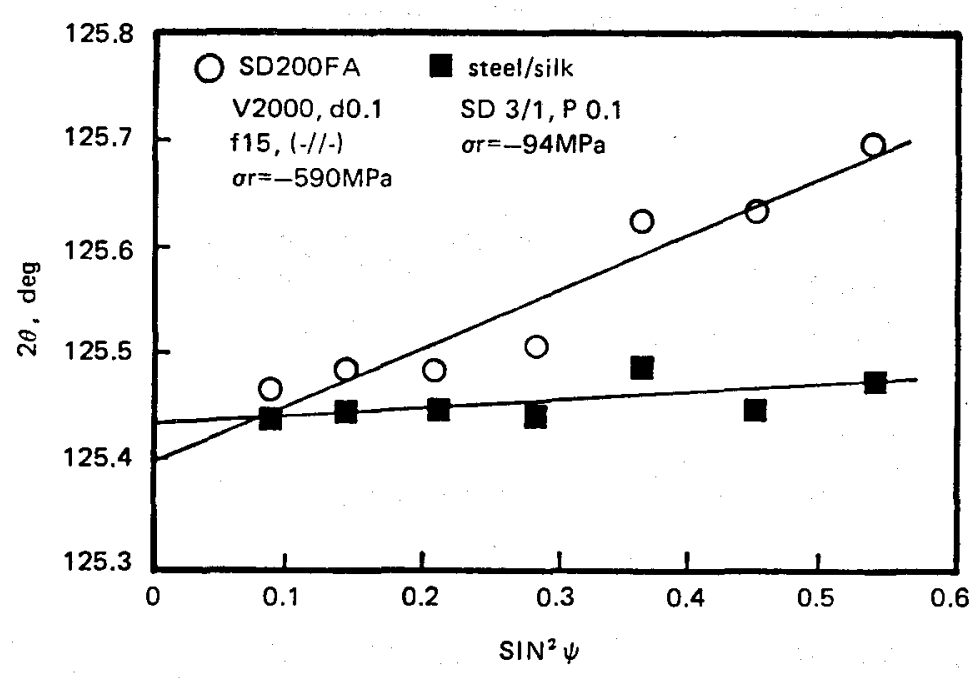

lower than the depth of the grinding flaw which was supposed about $40 \mu \mathrm{m}$. Therefore, the measured stress indicates the mean value of residual stress generated in the shallow layer from the surface. From these results, it was considered that the compressive stress layer in the ground surface had not enough depth to strengthen the sample ground perpendicular to the length of the specimen.

\section{Conclusions}

The bending strength of silicon nitride ground high efficiently was investigated by using machining center and diamond wheels.

(1) Using a machining center with high rigid spindle, the high efficient grinding could be done with resin bonded or metal bonded diamond wheels as well as with cast iron bonded wheel.

(2) There was no significant decrease in bending strength of samples ground parallel to the direction 
of bending stress with $0.1 \mathrm{~mm}$ depth of cut and 15 $\mathrm{m} / \mathrm{min}$ feed speed. The compressive residual stress of $590 \mathrm{MPa}$ was generated in the ground surface.

(3) In the case of the grinding perpendicular to the direction of bending stress, there was $40 \%$ decrease in strength compared with the grinding parallel to the direction of bending stress. The depth of machining flaw in the ground surface was about $40 \mu \mathrm{m}$.

\section{Acknowledgements}

The authors express their gratitude to Prof. T. Uematsu, Toyama Prefectural College of Technology, Prof. T. Nakagawa, Institute of Industrial Science, The University of Tokyo, and Ass. Prof. K. Suzuki, Nippon Institute of Technology, for guidance on this study and to Ass. Prof. K. Tanaka, Kyoto University, for $\mathrm{X}$-ray residual stress measurement.

\section{REFERENCES}

1) K. Suzuki, T. Uematsu and T. Nakagawa: Proc. Spring Japan Soc. Precision Engineering Meeting, Japan Soc. Precision Eng., Tokyo, (1985), 809.

2) R. W. Rice and J. J. Mecholsky: Nat. Bur. Stand. spec. publ. 562, ed. by B. J. Hockey and R. W. Rice, Nat. Bur. Stand., Washington D.C., (1979), 351.

3) S. Itoh: Tool Engineer, 27 (1983), No. 6, 49.

4) K. Takase, H. Kako and S. Kawakami: Toyota Eng., 35 (1985), 39.

5) M. Imai and R. Yamada: Toyoda Machine Works Tech. Rep., 26 (1986), No. 3.4, 12.

6) K. Tanaka, T. Kurimura, E. Matsui and Y. Akiniwa: $J$. Soc. Mater. Sci. Jpn., 36 (1987), 817.

7) T. Uematsu, K. Suzuki, T. Narita and T. Nakagawa: Proc. Spring Japan Soc. Precision Engineering Meeting, Japan Soc. Precision Eng., Tokyo, (1987), 589. 